\title{
Accounting and Analysis in Managing the Cost Of Innovation
}

\author{
Nesterov V.N. ${ }^{a}$ \\ Akhtyamova A.Sh. ${ }^{b}$ \\ Domracheva E.S.c \\ a bc Kazan Federal University, Institute of Management, Economics and Finance, Kazan, 420008, Russia
}

\section{Doi:10.5901/mjss.2015.v6n1s3p217}

\begin{abstract}
The article reveals the theoretical and practical aspects of accounting and analysis in managing the cost of innovation. Innovation process is a process of successive transformation of ideas into goods including stages of basic and applied research, engineering development, marketing, production and distribution. The purpose of accounting and analysis in managing the cost of innovation is to find a solution that would best meet the needs of all participants in the innovation process, and provide the required level of profitability of the project costs.
\end{abstract}

Keywords: innovation, innovation process, the life cycle of innovation, innovation cost management, innovation life-cycle.

\section{Introduction}

Development of exchange relations in the Russian economy, its integration into the international economic system requires the development of economic relations in accordance with international standards. In global practice, management of scientific and technological progress and introduction of its results into production is called innovation [4].

The defining characteristic of IP is the innovation cycle, whose design and effectiveness of the realization determine final operation results of the whole management system of scientific and technological advance. The innovation cycle is composed of interconnected and interdependent elements - steps and stages that form a complex whole - a system. The end result of this process is an innovation as a change implemented and used [11].

Innovation cycle for a particular object (a new product, process) is called the life cycle of innovation (ILC).

Applying the concept of life cycle to management of innovation costs, in our opinion, is particularly important, as it allows a systematic and comprehensive approach to the study of processes that take place within the framework of the innovation process, to trace the formation of costs for product of labor, to assess their effectiveness based on final results rather than on interim ones [12]. It is necessary to clearly distinguish, define, identify and analyze all steps and stages of the innovation cycle, as this affects the specificity of formation and the amount of costs that can reasonably be attributed to innovation.

\section{Theory}

Innovation life-cycle, as a rule, is the period of time from the idea generation, creation and dissemination of innovations to its use and disposal. It can be considered as an object of study as a whole or in the form of relatively isolated independent processes with their goals, final product, and the structure of the processes for its realization [1].

Product life cycle has time, labor and cost estimates used to manage, and is the most important characteristic of innovation, whose content defines the sequence and features of the processes occurring when innovative project passes its separate stages and phases. All they can be characterized by a set of goals and objectives, the specifics of methods and means to achieve them, the organizational form and the magnitude of costs for their implementation, the uncertainty degree of the expected results. When managing innovation product life cycle, one can systematically affect the efficiency of the innovation process and the management of the enterprise.

Life-cycle theory as a control object has become widespread in the theory and practice of management in consideration of a problem. The relevance of studying cycles is caused by integrated systems approach to improving the management of economic and innovative development, accelerating the introduction of scientific and technological achievements into practice, increasing the commercial effectiveness of product and production [3]. 
The concept of innovation life cycle, in our view, can be used to solve problems in quality management and product costs. In the solution of this problem pre-production stage plays a significant role which creates conditions for increasing efficiency of the entire life cycle. It is the most important for successful realization of innovations. It is in the early stages that basic qualitative, cost and other technical and economic indicators of innovations start to form [6]. Making inefficient management decisions in the early stages of the product life cycle may entail unreasonably high costs in its later stages. At the same time technical parameters adopted in designing products and processes required for their achievement limit the effective impact on the cost in the subsequent stages. Therefore, developers should formulate and solve not only technical problems, but also the ones which are specifically associated with future costs, so costs must be seen from the stage of pre-project studies.

Separate consideration of the features of the total costs formation according to stages and phases of life cycle greatly enhances the cost management opportunities throughout the innovation process, improving its information security and contributing to the search for reserves to reduce overall costs [2].

Innovation life cycle is a complex multistep process which is characterized by various specific relatively independent components in the form of separate phases and stages. Nevertheless, it should be noted that the ultimate objective of the entire innovation process should be seen as dominant in the organization of the management of separate life cycle stages. Thus, inadequate account of consumption for the conditions of a market economy leads to disunity in the individual stages of innovation process. This is evident, first, in an underestimation of the resulting impact of an intermediate stage on another in getting optimal values, and secondly, in almost complete absence of account of the probabilistic nature of the innovations development in time and the associated high risk of getting the expected results in consumption [5].

The concept of innovation life cycle has already found its application in the development of the domestic complex quality management system (DCQMS) and received positive comments.

\section{Results}

Investigation of the current system of innovation cost management shows that it still does not meet the principles of consistency and comprehensiveness. Individual elements and units of cost management in the innovation process have evolved and are being still developed largely in isolation and without sufficient focus on the ultimate goals of management [9]. It is developed separately in each economic unit, without proper alignment between the individual stages of the innovation process, which ultimately reduces the effectiveness of cost management system. There are also significant opportunities to improve cost management at the individual stages of life cycle.

As certain shortcomings of existing methods of cost management can be named the following:

- lack of forecasting and control of the total costs, defining their structure by innovation life cycle stages;

- cost management by economic units, but not by product;

- cost planning based on performance criteria of a specific economic unit without considering the interests of all LC participants;

- lack of a strategy to reduce the cost by products and LC participants;

- lack of continuity in decision-making by life cycle stages.

Improving the efficiency of innovation and its life cycle is ensured by coordinated action of three groups of factors:

1) planning economic indicators which should precede engineering design, focusing the developers on the economically effective solutions. Economic planning made in an early stage of innovation development allows to include such consumer and cost options that guarantee commercial success and effect. Economic planning covers the entire life cycle of innovation, that is, the period during which it manifests the effect allowed for, costs of such a design are not more than $3-5 \%$ of the total appropriations for the development, but they are one of the most important factors for the effectiveness of innovations;

2) the very activity in $R$ \& $D$ which should not be a limited autonomous system, and is an important element that plays an active role in ensuring not only technical solutions, but also economic tasks. The main purpose of this unit is to create a product with the specified technical and economic parameters that takes into account the latest scientific and technological developments and meets the best world standards;

3) production and sales of new products which forms and shows the final effect of $R$ \& $D$ for both the producer and the consumer. It should be noted that the highest efficiency of the innovation life cycle can be achieved only if there is contingence of all the elements and processes for the development of the product, its production, organizational structures, management systems of production and marketing [7].

To manage the innovation process and to achieve high economic efficiency of the final result, it is important to 
create an information base for decision-making and take into account the characteristics of each stage. The information content at different stages of the innovation process, in our opinion, should address the aspects presented in Table 1.

Table 1. Information base of innovation life cycle stages

\begin{tabular}{|l|l|}
\hline Stage & Information \\
\hline \multirow{5}{*}{ Pre-project } & $\begin{array}{l}\text { information about technological developments in the innovations market coming from the research } \\
\text { and development departments, marketing departments; about enterprise's potential for the } \\
\text { development and mastering new products, determining the degree and size of the risk; about target } \\
\text { markets and trends. At this stage output parameters of the goods or services should be determined, } \\
\text { as well as the need for products, the way to meet the needs, the main quality parameters based on } \\
\text { the products attractiveness for customers, cost, schedules, scope and form of marketing }\end{array}$ \\
\hline $\begin{array}{l}\text { information relating to new product ideas, their feasibility; differences and similarities of new and } \\
\text { base products are revealed as well as new product compliance with specialization of the enterprise; } \\
\text { the patent purity of the future product, its technical and economic characteristics are determined, } \\
\text { the quality and consumer properties are evaluated; the economic efficiency of a new product is } \\
\text { analyzed; demand and sales volumes are forecast; expenditures for creation and development of } \\
\text { new products are determined, as well as lead time, the necessary resources for the production of } \\
\text { new products, the payback period; entry into a market; profitability of new products is analyzed and } \\
\text { assessed }\end{array}$ \\
$\begin{array}{l}\text { Output planning for each unit engaged in the manufacture of a new product; creating a sample and } \\
\text { technical testing; studying product prices and other commercial conditions in the limited market; } \\
\text { choice of distribution channels, means and methods of advertising.. }\end{array}$ \\
\hline new product manufacture
\end{tabular}

At the stages of research and new product development, it is important to establish a correlation of expenditure for these purposes, the volume of sales, operating costs and profits, as well as to assess the payback of the development, production, marketing and advertising (usually this period will not exceed five years from the start of mass production until the break-even point).

A decision to start manufacturing a new product is based on the calculation of sales, cost of production, the degree of satisfying demand and supply, the stability of relations with customers; capacities, resources; the total investmenst in production and distribution, the expected profits for the accounting period, positive cash flow.

To realize the target criterion of efficiency it is necessary to create economic controlling mechanism for costs and benefits whose main components should be planning, recording and analysis. Constructing cost management system should be based on the modern principles and methods incidental to market economy, and take into account international standards. In particular, it is necessary to use such concepts and methods of cost management as controlling, management accounting, functional cost analysis, modern methods of economic evaluation of innovative projects which are adequate for market economy [10].

Planning functions will include project, regulatory and planning calculations; budgeting preparation and development of production, the production itself, the cost of production and service management, and other complex costs attributable to individual products in proportion to the reasonable bases; preparing a plan to reduce the cost of production by items of cost and factors. A special feature of this function is to determine the total costs of the life cycle and to use them as a target criterion in planning costs for new products by separate stages, steps in each organization involved in the implementation of the product life cycle [8].

Accounting requires the following activities:

- scientific and technical substantiation of norms and standards;

- the creation of regulatory services,

- budgeting productive resources,

- operational control over compliance with the regulations and cost estimates,

- - taking into account changes in regulations,

- current accounting and control of administrative and general costs and their distribution,

- drawing up cost-information reports,

- establishing cost and responsibility centers. Regulation function includes the work to prevent and to reduce losses from inefficient, unproductive utilization of material, labor and financial resources, to take measures for the adjustment of the rules, regulations and plans (budgets) of all types of resources, to increase the volume of work and products, timely implementation of plans for scientific and technical development. All of these 
activities should be aimed at achieving a given level of total expenses which is the main objective criterion.

The above mentioned work to be performed by the various functions of cost management should be linked to each other, and should be in accordance with the following principles:

- substantiating decisions to create and to manufacture new products along with already being manufactured or to replace obsolete ones;

- creation of scientifically-based norms and standards which at most reflect planned achievements of NTP and requirements of competition;

- planning production cost and its individual types, estimating costs based on progressive norms of expenditure of living labor and materialized labor, taking into account saving from the introduction of new technology and organizational and technical measures in the planning period;

- organization of cost accounting by their places of origin, centers of responsibility, identifying deviations of actual costs from the established norms, budgets by reasons, perpetrators of overspending or initiators of cost savings;

- systematic changes in the norms and standards of costs and their daily account to control economic efficiency of organizational and technological measures to improve the production and management;

- consolidation and analysis of information about deviations from the norms, estimates and about changes in rules and regulations by places of cost origin, by causes and perpetrators of deviations and initiators of change;

- improving methods for monitoring and analysis of production cost in all stages of the innovation life cycle, starting with the pre-production stage which includes project development of new products, to the exploitation by consumer;

- creation of an up-to-date information base which satisfies the requirements of operational management of economic processes and enables management to make better decisions about how to reduce costs and reserves and the cost of production;

- relationship of material and moral incentives to reduce costs in all stages of its formation and responsibility measures in case of overruns, wastage and losses in the design, valuation and costs planning stages;

- use of data consolidation and analysis of deviations from the norm, changes in regulations and budgets to make corrections, for vision and evaluation of the economic performance of units and evaluation of managers.

An important means of cost management system is a management accounting system whose the operation involves: determination of costs needed to achieve the planned objectives by centers of their origin, by product, by each project which are reflected in the planned indicators and regulations; account of actual costs and the identification of deviations from the plans.

\section{Conclusions}

For the effective operation of the developed control system all structural units whose activities affect the cost and result should be clearly defined. Each unit receives the status of the center of responsibility which is delegated the appropriate authority. When deciding on the establishment of organizational structures of management costs in the enterprise it is necessary to determine not only the unit responsible for the costs, but also cost objects, that is products and services. In the sphere of innovation cost object is a project development, event, order.

The purpose of the innovative project is to find solutions that can best meet the need, perform certain functions, which should provide the desired profitability level of the project costs. Perfection of the innovative project results can be expressed in quantitative ratio of outcomes and costs both for the project as a whole, and to some extent for its individual functions. The feasibility and value analysis enables to combine economic (cost) and technical aspects of a project, an item, a product. Cost analysis allows to minimize the costs and expenses which are necessary to carry out certain types of work (design, project and technological, research and experimental, etc.). Performance results utility in innovation is manifested in relative saving of follow-up costs when producing and operating, or directly when creating objects.

\section{References}

Blanco, E., Rey-Maquieira, J., Lozano, J. 2009 The economic impacts of voluntary environmental performance of firms: A critical review // Journal of Economic Surveys 23 (3), pp. $462-502$

Chiang, S., Lee, P., Anandarajan, A. 2012 The effect of $r \& d$ tax credit on innovation: A life cycle analysis // Innovation: Management, Policy and Practice 14 (4), pp. 510-523 
Bagautdinova, N.G., Galieva, G.T., Pakhmutov, Y.O., Pratchenko, O.V. 2014 Methods of regulation of processes of innovation business development //Mediterranean Journal of Social Sciences 5 (12), pp. 75-79.

Dosi, G., Nelson, R.R. 2010 Technical change and industrial dynamics as evolutionary processes, Handbook of the Economics of Innovation 1 (1 C), pp. 51-127

Safina, D., Podgornaya, A. (2014). Mobbing as an organizational phenomenon impeding implementation of changes. Mediterranean Journal of Social Sciences, 5 (18 SPEC. ISSUE), pp. 187-192

Kuznetsov, N. 2014 Management innovation companies based business cost indicators //Asian Social Science 10 (17), pp. 101-107

Patala, S., Jalkala, A., Soukka, R. 2014Methods for reducing buyer perceived risk related to the adoption of technological innovations // International Journal of Procurement Management 7 (1), pp. 71-84

Peitz, M., Shin, D. 2013Innovation and waste in supply chain management //Journal of Economic Behavior and Organization 86, pp. 191-199

Nagimova, A.M., Safiullina, F.R. (2014). Combination of university training with employment among Kazan' students. Sotsiologicheskie Issledovaniya, (4), pp. 121-124.

Peltoniemi, M. 2011Reviewing industry life-cycle theory: Avenues for future research //International Journal of Management Reviews 13 (4), pp. 349-375

Randall, A. 2011 Innovation, risk, precaution, and the regulation of GM crops Frontiers of //Economics and Globalization Source of the Document 10, pp. 337-367

Rammer, C., Czarnitzki, D., Spielkamp, A. 2009 Innovation success of non-R\&D-performers: Substituting technology by management in SMEs // Small Business Economics 33 (1), pp. 35-58

Safiullin, L.N., Shigabieva, A.M., Mazitov, V.M., Saipullaev, U.A. 2014 Some methodological foundation of an innovation theory//Life Science Journal 11 (6 SPEC. ISSUE), pp. 388-391

Shaidullin, R.N., Ulesov, D.V., Shigabieva, A.M., Safiullin, L.N. 2013 Innovative infrastructure in post-industrial society // World Applied Sciences Journal 27 (13), pp. 180-183 